\title{
Progression of breast cancer following locoregional ipsilateral recurrence: importance of interval time
}

\author{
Jennifer C Melvin ${ }^{1}$, Arnie D Purushotham ${ }^{2,3}$, Hans Garmo ${ }^{1,4}$, Sarah E Pinder ${ }^{2,3}$, lan S Fentiman ${ }^{2}$, \\ Cheryl Gillett ${ }^{2}$, Anca Mera ${ }^{1}$, Margreet Lüctehnborg ${ }^{4}$, Lars Holmberg ${ }^{1,4,5}$ and Mieke Van Hemelrijck ${ }^{\star}, 1$ \\ ${ }^{1}$ King's College London, Division of Cancer Studies, Cancer Epidemiology Group, Guy's Hospital, 3rd Floor, Bermondsey Wing, \\ London SE1 9RT, UK; ${ }^{2}$ King's College London, Division of Cancer Studies, Section of Research Oncology, London, UK; ${ }^{3} G u y ' s$ and \\ St Thomas' NHS Foundation Trust, London, UK; ${ }^{4}$ King's College London, Division of Cancer Studies, Section of Cancer \\ Epidemiology and Population Health, London, UK; ${ }^{5}$ Regional Cancer Centre, Uppsala/Örebro, Uppsala, Sweden and \\ ${ }^{6}$ Department of Surgical Sciences, Uppsala University, Uppsala, Sweden
}

Background: Studies comparing prognosis of breast cancer (BC) patients with and without locoregional recurrence (LR) present conflicting results. We aimed to improve our understanding of the impact of LR on prognosis by examining a large cohort of patients treated at Guy's and St Thomas' NHS Foundation Trust.

Methods: Risk factors associated with BC-specific death were investigated using Cox proportional hazards regression in 5199 women diagnosed between 1975 and 2007. Breast cancer-specific death following LR was assessed with Poisson regression.

Results: Overall, 552 women (11\%) developed LR, with a median follow-up time of 4.28 years. Known factors associated with BC-specific death (tumour stage, grade, and nodal status) were of significance in our data. Women with a shorter disease-free interval had a worse prognosis. For instance, the HR for BC-specific death among women undergoing mastectomy with an LR 0.5-1 year after diagnosis of their primary tumour was 6.67 (95\% Cl: 3.71-11.99), when compared with women who did not experience LR.

Conclusions: It often remains difficult to distinguish between a genuine LR and a new primary. The HRs for risk of BC-specific death following a second lesion suggest that they may act as a marker of systemic disease, large tumour burden, or depleted host defence. The clinically highly relevant impairment in prognosis calls for further research into the underlying mechanisms. We showed that for at least 15 years of follow-up, the prognosis in women following the occurrence of an LR may benefit from careful diagnostic and therapeutic management.

The influence of locoregional recurrences (LR) on the risk of breast cancer progression is not fully understood (Halverson et al, 1992; Willner et al, 1997; Koscielny and Tubiana, 1999; Elkhuizen et al, 2001; van Duijnhoven et al, 2011). Current evidence indicates worse outcomes following LR (Halverson et al, 1992; Willner et al, 1997; Elkhuizen et al, 2001; van Duijnhoven et al, 2011) or a worse prognosis associated only with specific LR tumour subtypes (Koscielny and Tubiana, 1999). It has been suggested that a shorter disease-free interval between the diagnosis of the primary tumour and a second lesion is a determinant of poor prognosis (Vicini et al, 2003; Komoike et al, 2006; Anderson et al, 2009; Botteri et al, 2010; Vichapat et al, 2011; Tanis et al, 2012; van Laar et al, 2013), and a short interval usually signals that distant metastasis has already occurred (van der Sangen et al, 2013). In one paper, the Early Breast Cancer Trialists Collaborative Group (EBCTCG) showed that in up to $25 \%$ of cases LR was likely

*Correspondence: Dr M Van Hemelrijck; E-mail: mieke.vanhemelrijck@kcl.ac.uk

Received 3 February 2015; revised 15 July 2015; accepted 10 August 2015; published online 10 December 2015

(c) 2016 Cancer Research UK. All rights reserved 0007-0920/16 
Table 1. Descriptive characteristics by locoregional recurrence status, including women with a primary diagnosis between the years of 1975 and 2007

\begin{tabular}{|c|c|c|}
\hline & $\begin{array}{l}\text { Locoregional } \\
\text { recurrences } \\
(N=552)\end{array}$ & $\begin{array}{l}\text { No locoregional } \\
\text { recurrences } \\
(N=4502)\end{array}$ \\
\hline & $N(\%)$ & $N(\%)$ \\
\hline \multicolumn{3}{|l|}{ Age at diagnosis (years) } \\
\hline$\leqslant 49$ & 163 (31.59) & $1206(29.20)$ \\
\hline $50-59$ & $156(30.23)$ & $1079(26.13)$ \\
\hline $60-69$ & $96(18.60)$ & $1019(24.67)$ \\
\hline$\geqslant 70$ & $101(19.57)$ & $826(20.00)$ \\
\hline \multicolumn{3}{|l|}{ Mean follow-up (years) } \\
\hline Time from primary to death (s.d.) & $10.35(7.50)$ & $12.16(8.57)$ \\
\hline \multicolumn{3}{|l|}{ Tumour side } \\
\hline Left & $260(47.10)$ & $2267(50.63)$ \\
\hline Right & $253(45.83)$ & $2094(46.51)$ \\
\hline Unknown & $39(7.07)$ & $141(3.13)$ \\
\hline \multicolumn{3}{|l|}{ Menopausal status } \\
\hline Pre & $200(36.23)$ & $1415(31.43)$ \\
\hline Peri & $56(10.14)$ & $288(6.40)$ \\
\hline Post & $296(53.62)$ & 2799 (62.17) \\
\hline \multicolumn{3}{|l|}{ Family history } \\
\hline First degree & $57(10.33)$ & $518(11.51)$ \\
\hline Second degree & $38(6.88)$ & $306(6.80)$ \\
\hline None & $417(75.54)$ & 3092 (68.68) \\
\hline First and second degree & $14(2.54)$ & $93(2.07)$ \\
\hline Third degree & $0(0.00)$ & $21(0.47)$ \\
\hline Missing & $26(4.71)$ & $472(10.48)$ \\
\hline \multicolumn{3}{|l|}{ No. of pregnancies } \\
\hline 0 & $105(22.11)$ & $716(22.16)$ \\
\hline $1-2$ & $212(44.63)$ & $1395(43.18)$ \\
\hline $3-4$ & $118(24.84)$ & $855(26.46)$ \\
\hline$>4$ & $39(8.21)$ & $243(7.52)$ \\
\hline Missing & $1(0.21)$ & $22(0.68)$ \\
\hline \multicolumn{3}{|l|}{ Tumour size at diagnosis $(\mathrm{cm})$} \\
\hline$<2$ & $107(19.38)$ & 1507 (33.47) \\
\hline $2-3$ & $144(26.09)$ & $1122(24.92)$ \\
\hline$>3$ & $301(54.53)$ & $1873(41.60)$ \\
\hline \multicolumn{3}{|l|}{ Invasive grade } \\
\hline Grade 1 & $38(6.70)$ & $622(13.43)$ \\
\hline Grade 2 & $218(38.45)$ & $1724(37.22)$ \\
\hline Grade 3 & $202(35.63)$ & 1470 (31.74) \\
\hline Missing & $109(11.78)$ & $816(17.62)$ \\
\hline \multicolumn{3}{|l|}{ Invasive type } \\
\hline Ductal not otherwise specified & $434(78.62)$ & $3580(79.52)$ \\
\hline Lobular & $67(12.14)$ & $456(10.13)$ \\
\hline Other & $5(0.91)$ & $72(1.60)$ \\
\hline Missing & $46(8.33)$ & $394(8.75)$ \\
\hline \multicolumn{3}{|l|}{ Oestrogen receptor status } \\
\hline Negative & $171(30.98)$ & $1052(23.37)$ \\
\hline Positive & $330(59.78)$ & $3029(67.28)$ \\
\hline Missing & $51(9.24)$ & $421(9.35)$ \\
\hline \multicolumn{3}{|l|}{ Progesterone receptor status } \\
\hline Negative & 259 (46.92) & 1709 (37.96) \\
\hline Positive & $230(41.67)$ & 2318 (51.49) \\
\hline Missing & $63(11.41)$ & $475(10.55)$ \\
\hline \multicolumn{3}{|l|}{ HER2 status } \\
\hline Negative & $223(40.40)$ & $1970(43.76)$ \\
\hline Positive & $70(12.68)$ & $525(11.66)$ \\
\hline Missing & $259(46.92)$ & 2007 (44.58) \\
\hline \multicolumn{3}{|l|}{ Operation type } \\
\hline Mastectomy & $249(45.11)$ & $2487(55.24)$ \\
\hline Breast conservation & $302(54.71)$ & $2011(44.67)$ \\
\hline Other surgery & $1(0.18)$ & $4(0.09)$ \\
\hline
\end{tabular}


Table 2. Multivariate HRs and $95 \% \mathrm{Cl}$ for risk of $\mathrm{BC}$ death by surgery type

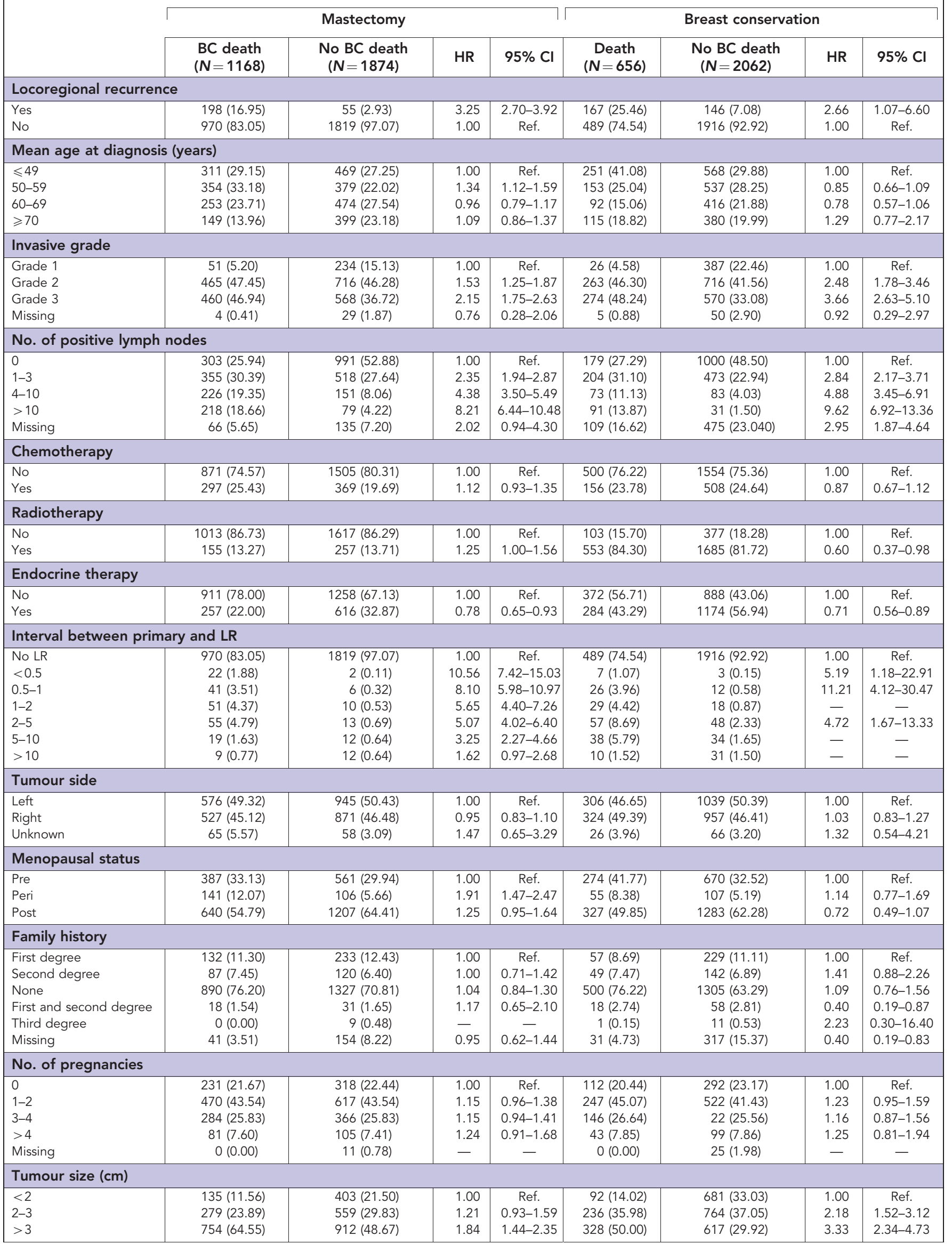




\begin{tabular}{|c|c|c|c|c|c|c|c|c|}
\hline & \multicolumn{4}{|c|}{ Mastectomy } & \multicolumn{4}{|c|}{ Breast conservation } \\
\hline \multicolumn{9}{|l|}{ Invasive type } \\
\hline $\begin{array}{l}\text { Ductal Not otherwise } \\
\text { specified }\end{array}$ & $921(78.85)$ & $1437(76.68)$ & 1.00 & Ref. & $559(85.21)$ & $1639(79.49)$ & 1.00 & Ref. \\
\hline Lobular & $152(13.01)$ & 220 (11.74) & 0.93 & $0.69-1.27$ & $55(8.38)$ & $178(8.63)$ & 0.58 & $0.32-1.06$ \\
\hline \multicolumn{9}{|c|}{ Oestrogen receptor status } \\
\hline Negative & $378(32.50)$ & $467(24.92)$ & 1.00 & Ref. & $216(32.93)$ & $365(17.70)$ & 1.00 & Ref. \\
\hline Positive & 699 (59.55) & $1221(65.15)$ & 0.81 & $0.69-0.95$ & 406 (61.89) & $1457(70.66)$ & 0.65 & $0.52-0.82$ \\
\hline Missing & $91(7.95)$ & $186(9.93)$ & 1.30 & $0.79-2.13$ & $34(5.18)$ & $240(11.64)$ & 0.20 & $0.06-0.63$ \\
\hline \multicolumn{9}{|c|}{ Progesterone receptor status } \\
\hline Negative & $580(49.66)$ & $743(39.65)$ & 1.00 & Ref. & $310(47.26)$ & $648(31.43)$ & 1.00 & Ref. \\
\hline Positive & $174(14.90)$ & 205 (10.94) & 1.37 & $1.11-1.70$ & $106(16.16)$ & $196(9.51)$ & 1.67 & $1.26-2.22$ \\
\hline Missing & $535(45.80)$ & $937(50.00)$ & 0.83 & $0.70-0.97$ & $230(35.06)$ & 907 (43.99) & 0.76 & $0.60-0.98$ \\
\hline \multicolumn{9}{|c|}{$\begin{array}{l}\text { Abbreviations: } \mathrm{BC}=\text { breast cancer; } \mathrm{Cl} \text {, confidence intervals; } \mathrm{HR}=\text { hazard ratios; } \mathrm{LR}=\text { locoregional recurrence. }- \text {, no estimate because of small numbers. Models were adjusted for age, tumour } \\
\text { grade, pathological nodal stage, treatment methods of the initial cancer (except where stated), and locoregional recurrence as a time-dependent variable. The upper (above the heading } \\
\text { 'Tumour side') section of the table represents a multivariable model including only covariates listed within this section. The following (below the heading 'Tumour side') section represents } \\
\text { models adjusted for all aforementioned variables. }\end{array}$} \\
\hline
\end{tabular}

The following variables were retrieved from the clinical database: age at diagnosis, period of initial diagnosis (1975-1979, 1980-1984, 1985-1989, 1990-1994, and after 1995), and tumour characteristics (clinical size, pathological lymph node status, histopathological type and grade, oestrogen and progesterone receptor status), as well as treatment given for the initial cancer. Follow-up information, including date of recurrence, date of last contact, and cause of death, was obtained from medical records as registered in the Hospital's Clinical Cancer Database. Cause of death was ascertained by national death certification obtained from the National Cancer Registry (Table 1). All data collection was carried out under NHS Research Ethics Committee approval (REC Number: 12/EE/0493).

Statistical analysis. We assessed how known clinicodemographic risk factors and LR effect risk of breast cancer-specific death using Cox proportional hazards regression analysis. All analyses were stratified by surgery type (mastectomy vs breast-conserving surgery (BCS)). Where cause of death was unknown, women who experienced distant metastases before death were considered to have died of breast cancer.

To investigate how time between primary diagnosis and LR affects breast cancer-specific death, we used LR as a time-varying covariate in a Cox proportional hazards model. To graphically illustrate the effect of time between primary diagnosis and LR on breast cancerspecific death, we used Poisson regression. These models estimate hazard curves for risk of breast cancer-specific death among women with and without LR whereby follow-up time is split as (i) time before development of LR and (ii) time after LR, using the logarithm of time at risk as an offset. Risk of breast cancer-specific death for women without LR was modelled through natural cubic splines with knots in quartiles of time-to-event. Risk of breast cancer-specific death for women with LR was similarly modelled through natural cubic splines with knots in tertiles of time-to-event with two additional restrictions: (i) risk of breast cancer-specific death because of LR was bound to be zero at the onset of LR; (ii) additional risk because of LR was bound not to be distinguished from the baseline risk after 20 years of follow-up. The risk because of LR was allowed to depend linearly on time between the two diagnoses.

These graphical analyses were not stratified by surgery type because there is good evidence to suggest that BCS is a feasible option for patients with tumours of up to $5 \mathrm{~cm}$. Higher incidences of LR have been reported in the longer term, but this does not appear to influence prognosis (van Dongen et al, 2000; Litiere et al, 2012).

All analyses were performed using SAS software version 9.3.1 (SAS Institute Inc., Cary, NC) and R version 2.15.3 (R Foundation for Statistical Computing, Vienna, Austria).

\section{RESULTS}

Demographics. Five hundred and sixty-seven women developed LR without a prior distant metastasis. The median interval between primary diagnosis and LR was 4.28 years (s.d. \pm 4.35 ). There was no statistically significant difference in age at primary diagnosis between women with $(56.35$ years (s.d. \pm 13.6$)$ ) and without LR (58.7 years (s.d. \pm 12.1$)$ ). There was no difference in family history of breast cancer between the two groups (Table 1).

Risk of breast cancer death: entire study population. Table 2 shows that women with a shorter time interval to LR had an increased risk of breast cancer-specific death compared with women with a longer interval, (e.g., the HR for women who underwent mastectomy in those who experienced an LR within 6 months of primary diagnosis was 10.56 (95\% CI: 7.42-15.03), whereas the HR for LR occurring $>10$ years following primary diagnosis was 1.62 (95\% CI: 0.97-2.68), when compared with a reference group of women who did not develop LR).

Risk of BC death-LR subgroup. A multivariate analysis looking at the association between known clinicodemographic risk factors and breast cancer-specific death (Table 2) was repeated in the subgroup of women who experienced LR (Table 3 ). We observed 
Table 3. Multivariate HRs and $95 \% \mathrm{Cls}$ for risk of $\mathrm{BC}$ death following local recurrence by surgery type

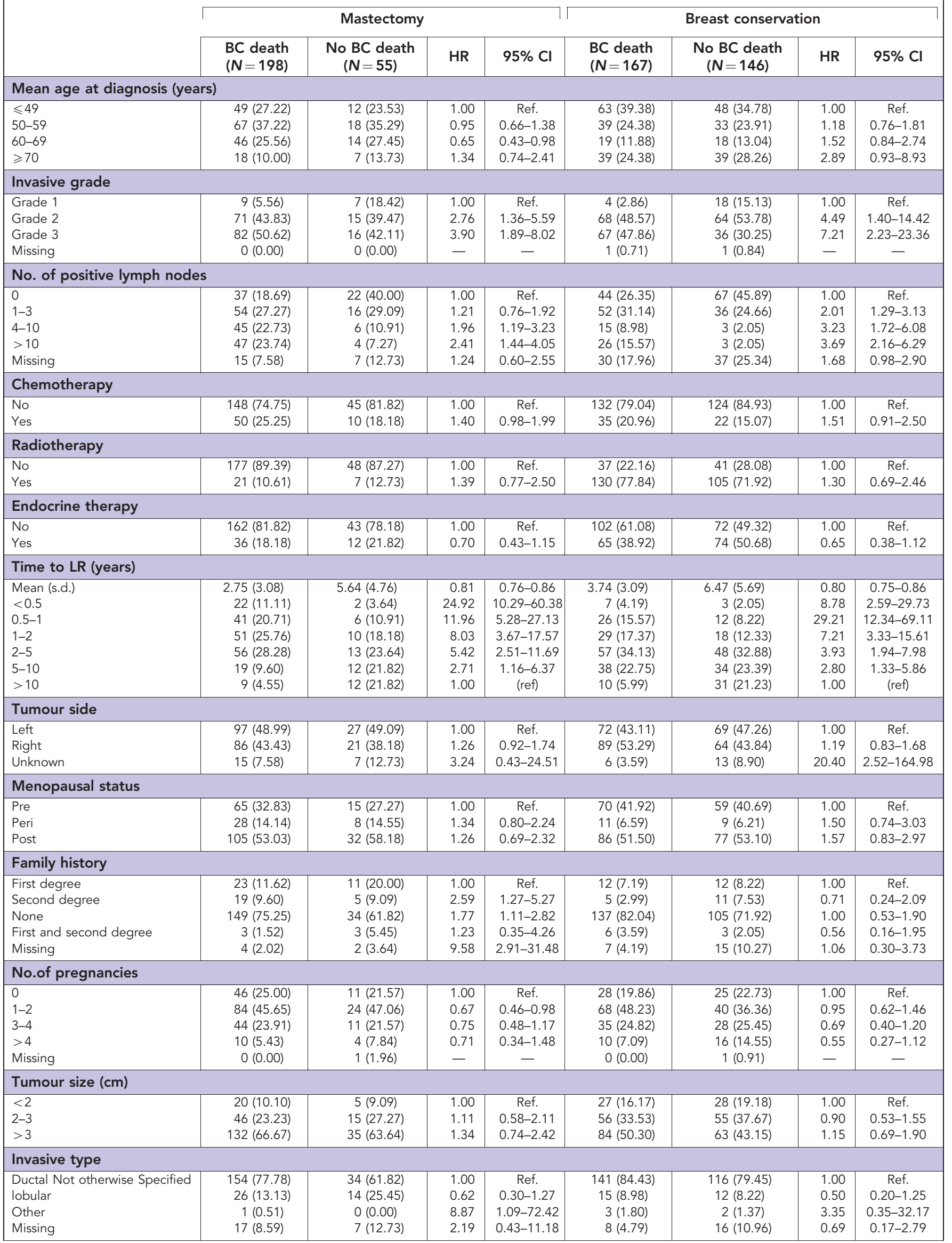




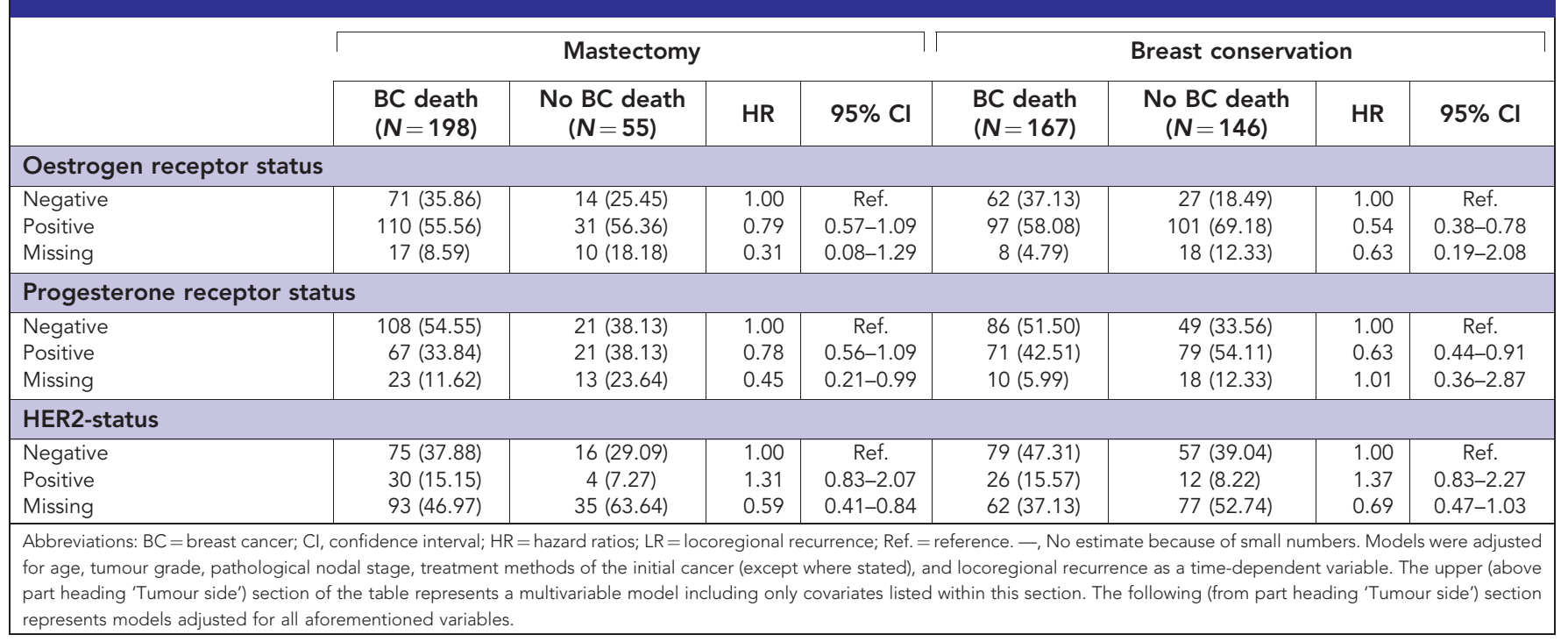

decreased risk of $\mathrm{BC}$-specific death as the time interval between primary tumour and LR increased. For instance, the HR for LRs occurring within 6 months of the primary tumour was $13.76(95 \%$ CI: 7.08-26.74), when compared with a reference group where LRs occurred $>5$ years following primary diagnosis in women who underwent mastectomy.

Figure 1 demonstrates a sharp increase in the hazard of breast cancer-specific death for women diagnosed with LR soon after diagnosis of their primary breast tumour relative to later occurring LRs, as observed in the HRs (Table 3). The magnitude of this hazard declines continuously with time, but does not return to that of the level of women not experiencing an LR, even 20 years after the diagnosis of their primary diagnosis. These curves were replicated by year of primary diagnosis (1975-1989 and 1990-2007), by surgery type, and for breast recurrences only; all patterns remained consistent (Figure A1 in Appendix).

\section{DISCUSSION}

Women with LR had a considerably poorer prognosis with regard to breast cancer-specific death compared with those without LR, especially if the LR occurred close in time to primary diagnosis. The increase in risk after LR was still apparent 20 years postprimary diagnosis and at no point in time declined to the level of risk in women without LR at the corresponding time of follow-up.

Some studies reported a worse prognosis for women with LR compared with those without (Willner et al, 1997; Elkhuizen et al, 2001), whereas others found a similar prognosis for women with and without LR (Robinson et al, 1993). One study showed a 2-year survival of $53 \%$ following an LR, compared with $86 \%$ among nonrelapsed women (Willner et al, 1997). A further study found that patients who experienced an LR within 2 years of BCS were at especially high risk of distant metastasis and breast cancer-specific death (Elkhuizen et al, 2001).

Although the cited studies have touched on the possible effect of time interval, our study benefits from both long-term and complete follow-up allowing for a more in-depth and precise investigation into the importance of the timing of the LR. In our study, short interval time was the strongest determinant of risk for breast cancer-specific death following LR. The increased elevation of the

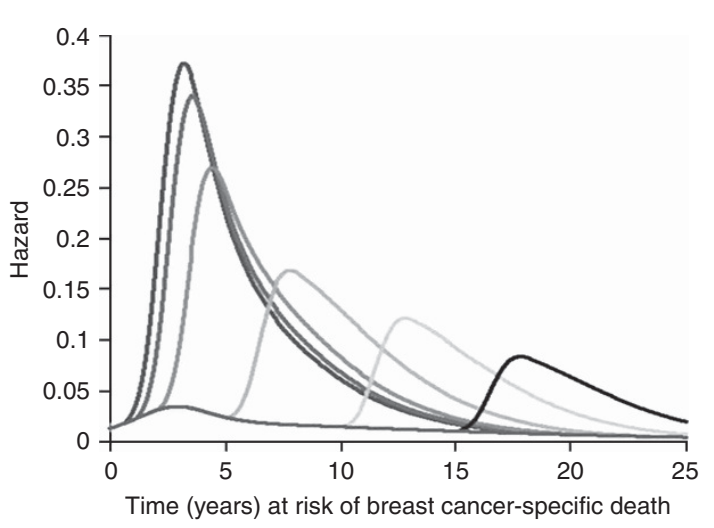

Figure 1. Estimated hazards of breast cancer death from Poisson regression model. The blue curve represents the hazard of breast cancer death for women without recurrence. The dark red, bright red, dark orange, light orange, yellow, and black curves represent the hazard of breast cancer death for local recurrence diagnosed at different interval times $(0.5,1,2,5,10$, and 15 years). There were 5194 women who did not experience a locoregional recurrence (LR) (blue line), 34 women experienced LRs within 6 months, 85 women within 1 year, 108 women between 1 and 2 years, 174 women within 2-5 years, 103 women between 5 and 10 years, and finally, 62 women experienced LRs between 10 and 15 years following their primary diagnosis.

hazard ratio for LR closer in time to primary tumour may suggest that a rapidly occurring LR may be an indication of an undetected existing distant disease. This is also supported by the fact that women with a shorter interval time often rapidly develop metastasis after LR (Macmillan et al, 1996; Elkhuizen et al, 2001; Komoike et al, 2006).

Our findings combined with existing literature may indicate that the decline in risk of breast cancer-specific death following LR as the time interval increases could be because of a proportion of these tumours being second primaries, as opposed to genuinely recurring, active disease (Holmberg et al, 1988; Hartman et al, 2007). A proportion of the second primaries should be localised disease with a chance to cure - and especially so if the women were under regular mammography surveillance. Later occurring LR may also be less aggressive recurrences, as opposed to rapidly growing 
lesions. Another plausible explanation for the association between the interval and breast cancer-specific death is that two tumours occurring close in time indicate a depleted host defence mechanism (von Mensdorff-Pouilly et al, 2000; de Visser et al, 2006).

Strengths and limitations. A strength of our study is the longterm and complete follow-up of a cohort of breast cancer patients, in which it was possible to measure breast cancer-specific survival. However, there are limitations that should be addressed. Histopathological tumour size was not available for all patients, and clinically assessed tumour size was used in its place. Although this measurement is less accurate, it did allow for a further way in which to rank patients by disease severity. Information on the tumour characteristics of LR were not included, and thus we are unable to infer the significance of their contribution towards prognosis. Furthermore, we could not use the characteristics of the primary and the LR to distinguish true recurrences from second primaries. We have no reason to believe that the treatment protocol at Guy's \& St Thomas' NHS Trust was different or in any way responsible for the higher estimates observed here of risk of breast cancer death following an LR compared with those observed in previous studies. Finally, additional information on treatment adherence and comorbidities may have confounded our observations. However, as all women were treated in the same Unit in the same Hospital, we are confident that we have included high-quality treatment data.

\section{CONCLUSION}

It remains difficult to distinguish between an LR and a new primary. However, our results of an increased risk of breast cancerdeath after an LR/new primary suggest that LR acts as a marker of systemic disease, large tumour burden, or depleted host defence and that the interpretation of this marker varies with interval to the primary lesion. The clinically highly relevant impairment in prognosis calls for further research into the underlying mechanisms, and indicates that for at least a 15-year follow-up the occurrence of an LR, a careful diagnostic and therapeutic management, is needed to improve the prognosis of affected women. These data further informs the design of post-treatment surveillance programs.

\section{ACKNOWLEDGEMENTS}

We thank the King's Health Partners Cancer Biobank, London, UK for providing the patient data used in this study. The study was supported by CRUK.

\section{CONFLICT OF INTEREST}

The authors declare no conflict of interest.

\section{REFERENCES}

Anderson SJ, Wapnir I, Dignam JJ, Fisher B, Mamounas EP, Jeong JH, Geyer Jr CE, Wickerham DL, Costantino JP, Wolmark N (2009) Prognosis after ipsilateral breast tumor recurrence and locoregional recurrences in patients treated by breast-conserving therapy in five National Surgical Adjuvant Breast and Bowel Project protocols of node-negative breast cancer. J Clin Oncol 27(15): 2466-2473.

Botteri E, Bagnardi V, Rotmensz N, Gentilini O, Disalvatore D, Bazolli B, Luini A, Veronesi U (2010) Analysis of local and regional recurrences in breast cancer after conservative surgery. Ann Oncol 21(4): 723-728. de Visser KE, Eichten A, Coussens LM (2006) Paradoxical roles of the immune system during cancer development. Nat Rev Cancer 6(1): 24-37. Early Breast Cancer Trialists' Collaborative GDarby S, McGale P, Correa C, Taylor C, Arriagada R, Clarke M, Cutter D, Davies C, Ewertz M, Godwin J, Gray R, Pierce L, Whelan T, Wang Y, Peto R (2011) Effect of radiotherapy after breast-conserving surgery on 10-year recurrence and 15 -year breast cancer death: meta-analysis of individual patient data for 10,801 women in 17 randomised trials. Lancet 378(9804): 1707-1716.

Elkhuizen PH, Hermans J, Leer JW, van d EVMJ (2001) Isolated late local recurrences with high mitotic count and early local recurrences following breast-conserving therapy are associated with increased risk on distant metastasis. Int J Radiat Oncol Biol Phys 50(2): 387-396.

Halverson KJ, Perez CA, Kuske RR, Garcia DM, Simpson JR, Fineberg B (1992) Survival following locoregional recurrence of breast cancer: univariate and multivariate analysis. Int J Radiat Oncol Biol Phys 23(2): 285-291.

Hartman M, Czene K, Reilly M, Adolfsson J, Bergh J, Adami HO, Dickman PW, Hall P (2007) Incidence and prognosis of synchronous and metachronous bilateral breast cancer. J Clin Oncol 25(27): 4210-4216.

Holmberg L, Adami HO, Ekbom A, Bergstrom R, Sandstrom A, Lindgren A (1988) Prognosis in bilateral breast cancer. Effects of time interval between first and second primary tumours. Br J Cancer 58(2): 191-194.

Komoike Y, Akiyama F, Iino Y, Ikeda T, Akashi-Tanaka S, Ohsumi S, Kusama M, Sano M, Shin E, Suemasu K, Sonoo H, Taguchi T, Nishi T, Nishimura R, Haga S, Mise K, Kinoshita T, Murakami S, Yoshimoto M, Tsukuma H, Inaji H (2006) Ipsilateral breast tumor recurrence (IBTR) after breast-conserving treatment for early breast cancer: risk factors and impact on distant metastases. Cancer 106(1): 35-41.

Koscielny S, Tubiana M (1999) The link between local recurrence and distant metastases in human breast cancer. Int J Radiat Oncol Biol Phys 43(1): 11-24.

Litiere S, Werutsky G, Fentiman IS, Rutgers E, Christiaens MR, Van Limbergen E, Baaijens MH, Bogaerts J, Bartelink H (2012) Breast conserving therapy versus mastectomy for stage I-II breast cancer: 20 year follow-up of the EORTC 10801 phase 3 randomised trial. Lancet Oncol 13(4): 412-419.

Macmillan RD, Purushotham AD, George WD (1996) Local recurrence after breast-conserving surgery for breast cancer. Br J Surg 83(2): $149-155$.

Robinson E, Rennert G, Rennert HS, Neugut AI (1993) Survival of first and second primary breast cancer. Cancer 71(1): 172-176.

Tanis E, van de Velde CJ, Bartelink H, van de Vijver MJ, Putter H, van der Hage JA (2012) Locoregional recurrence after breast-conserving therapy remains an independent prognostic factor even after an event free interval of 10 years in early stage breast cancer. Eur J Cancer 48(12): 1751-1756

van der Sangen MJ, Poortmans PM, Scheepers SW, Lemaire BM, van Berlo CL, Tjan-Heijnen VC, Voogd AC (2013) Prognosis following local recurrence after breast conserving treatment in young women with early breast cancer. Eur J Surg Oncol 39(8): 892-898.

van Dongen JA, Voogd AC, Fentiman IS, Legrand C, Sylvester RJ, Tong D, van der Schueren E, Helle PA, van Zijl K, Bartelink H (2000) Long-term results of a randomized trial comparing breast-conserving therapy with mastectomy: European Organization for Research and Treatment of Cancer 10801 trial. J Natl Cancer Inst 92(14): 1143-1150.

van Duijnhoven FJ, Bueno-De-Mesquita HB, Calligaro M, Jenab M, Pischon T, Jansen EH, Frohlich J, Ayyobi A, Overvad K, Toft-Petersen AP, Tjonneland A, Hansen L, Boutron-Ruault MC, Clavel-Chapelon F, Cottet V, Palli D, Tagliabue G, Panico S, Tumino R, Vineis P, Kaaks R, Teucher B, Boeing H, Drogan D, Trichopoulou A, Lagiou P, Dilis V, Peeters PH, Siersema PD, Rodriguez L, Gonzalez CA, Molina-Montes E, Dorronsoro M, Tormo MJ, Barricarte A, Palmqvist R, Hallmans G, Khaw KT, Tsilidis KK, Crowe FL, Chajes V, Fedirko V, Rinaldi S, Norat T, Riboli E (2011) Blood lipid and lipoprotein concentrations and colorectal cancer risk in the European Prospective Investigation into Cancer and Nutrition. Gut 60(8): 1094-1102.

van Laar C, van der Sangen MJ, Poortmans PM, Nieuwenhuijzen GA, Roukema JA, Roumen RM, Tjan-Heijnen VC, Voogd AC (2013) Local recurrence following breast-conserving treatment in women aged 40years or younger: trends in risk and the impact on prognosis in a population-based cohort of 1143 patients. Eur J Cancer 49(15): 3093-3101. 
Vichapat V, Garmo H, Holmberg L, Fentiman IS, Tutt A, Gillett C, Luchtenborg M (2011) Prognosis of metachronous contralateral breast cancer: importance of stage, age and interval time between the two diagnoses. Breast Cancer Res Treat 130(2): 609-618.

Vicini FA, Kestin L, Huang R, Martinez A (2003) Does local recurrence affect the rate of distant metastases and survival in patients with early-stage breast carcinoma treated with breast-conserving therapy? Cancer 97(4): 910-919.

von Mensdorff-Pouilly S, Verstraeten AA, Kenemans P, Snijdewint FG, Kok A, Van Kamp GJ, Paul MA, Van Diest PJ, Meijer S, Hilgers J (2000) Survival in early breast cancer patients is favorably influenced by a natural humoral immune response to polymorphic epithelial mucin. J Clin Oncol 18(3): 574-583.

Willner J, Kiricuta IC, Kolbl O (1997) Locoregional recurrence of breast cancer following mastectomy: always a fatal event? Results of univariate and multivariate analysis. Int J Radiat Oncol Biol Phys 37(4): 853-863.

This work is published under the standard license to publish agreement. After 12 months the work will become freely available and the license terms will switch to a Creative Commons AttributionNonCommercial-Share Alike 4.0 Unported License.

\section{APPENDIX}

\section{A}

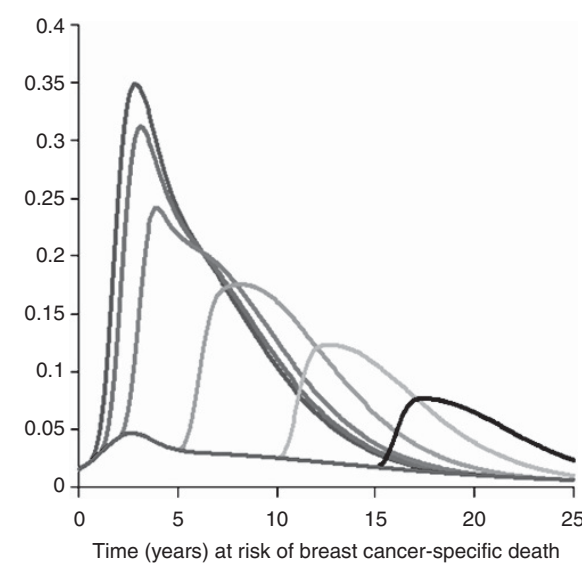

B

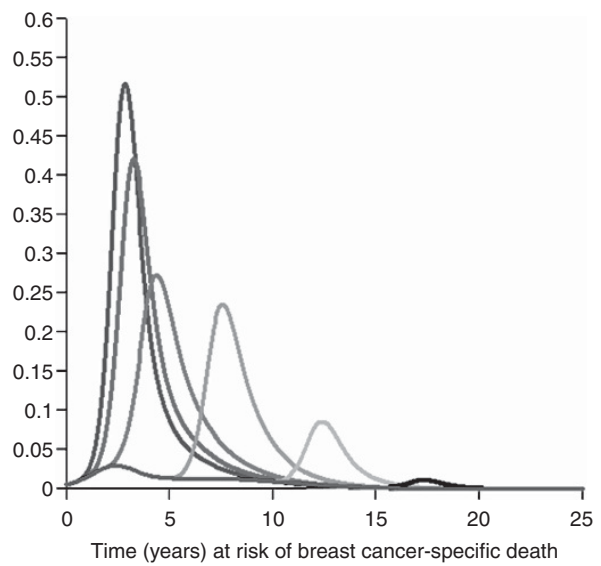

Figure A1. Estimated hazards of breast cancer death from Poisson regression model in (A) women diagnosed between 1975 and 1990 and (B) women diagnosed between 1990 and 2007. The blue curve represents the hazard of breast cancer death for women without recurrence. The dark red, bright red, dark orange, light orange, yellow, and black curves represent the hazard of breast cancer death for local recurrence diagnosed at different interval times $(0.5,1,2,5,10$, and 15 years). A full color version of this figure is available at British Journal of Cancer online. 